\title{
The bacA gene, which determines bacitracin susceptibility in Streptococcus pneumoniae and Staphylococcus aureus, is also required for virulence
}

Anti-Infective Research (UP1345), SmithKline Beecham Pharmaceuticals, 1250 South Collegeville Road, PO Box 5089, Collegeville, PA 19426-0989, USA

\author{
Alison F. Chalker, Karen A. Ingraham, R. Dwayne Lunsford, \\ Alexander P. Bryant, Joanna Bryant, Nicola G. Wallis, John P. Broskey, \\ Stewart C. Pearson and David J. Holmes
}

Author for correspondence: Alison F. Chalker. Tel: +1 610917 6366. Fax: +1 6109177901. e-mail: Alison_F_Chalker@sbphrd.com
Keywords: bacitracin, bacA, undecaprenol kinase, Staphylococcus aureus,
Streptococcus pneumoniae

Keywords: bacitracin, bacA, undecaprenol kinase, Staphylococcus aureus,
Streptococcus pneumoniae

\begin{abstract}
Homologues of Escherichia coli bacA, encoding extremely hydrophobic proteins, were identified in the genomes of Staphylococcus aureus and Streptococcus pneumoniae. Allelic replacement mutagenesis demonstrated that the gene is not essential for in vitro growth in either organism, and the mutants showed no significant changes in growth rate or morphology. The Staph. aureus bacA mutant showed slightly reduced virulence in a mouse model of infection and an eightfold increase in bacitracin susceptibility. However, a Strep. pneumoniae bacA mutant was highly attenuated in a mouse model of infection, and demonstrated an increase in susceptibility to bacitracin of up to $\mathbf{1 6 0 0 0 0}$-fold. These observations are consistent with the previously proposed role of BacA protein as undecaprenol kinase.
\end{abstract}


low and in cell-free preparations is limiting for the synthesis of both polymers (Baddiley, 1973). It has been suggested that UP availability controls the rate of cell wall synthesis (Anderson et al., 1972; Baddiley, 1973), so it is interesting that a further source of UP is provided by a membrane-bound undecaprenol phosphokinase activity which reversibly converts the $\mathrm{C}_{55}$ alcohol undecaprenol into UP (Higashi et al., 1970a; EC 2.7.1.66). As the majority of membrane-associated undecaprenol is present in the free alcohol form approximately $90 \%$ in both Staphylococcus aureus and Streptococcus pyogenes (Higashi et al., 1970b; Reusch \& Panos, 1976), $80 \%$ in late exponential phase Streptococcus faecalis (Umbreit et al., 1972) and $25 \%$ in exponential phase Lactobacillus plantarum, increasing to $73 \%$ in stationary phase cells (Thorne, 1973) - it appears that this apparently futile reaction has the capacity to play an important role in UP availability and regulation of cell wall biosynthesis.

The gene encoding undecaprenol kinase has not been definitively identified, but an Escherichia coli strain carrying the $b a c A$ gene on a multicopy plasmid displayed an increase in membrane-associated isoprenol kinase activity and reduced susceptibility to bacitracin without a concomitant increase in UPP synthetase activity (Cain et al., 1993). It was therefore hypothesized that bacA encodes undecaprenol kinase, and that when this enzyme is overproduced it is able to produce sufficient supplies of UP from undecaprenol to overcome the effects of UPP sequestration, thereby causing bacitracin resistance. However, Gram-negative bacteria are generally insensitive to bacitracin and, in the absence of the membrane-permeabilizing agent polymyxin $\mathrm{B}$, the growth of E. coli is unaffected up to bacitracin concentrations of $200 \mu \mathrm{g} \mathrm{ml} \mathrm{m}^{-1}$ (Toscano \& Storm, 1982; Cornelissen \& Van den Bossche, 1983). Hence very high concentrations of bacitracin were used in this study, and it is possible that under these conditions the observed response to bacitracin reflects alternative or additional effects, such as non-specific toxicity or membrane permeabilization. We therefore wished to characterize the role of the bacA gene in bacitracin-susceptible Grampositive organisms. Here we describe the identification of the bacA genes of the Gram-positive organisms Staph. aureus and Streptococcus pneumoniae, and examine the effect of bacA mutagenesis on viability, virulence and bacitracin susceptibility.

\section{METHODS}

Bacterial strains and plasmids. Strep. pneumoniae 0100993 (NCIMB 40794; serotype 3) is a plasmid-free, encapsulated clinical isolate kindly provided by D. Felmington (University College Hospital, London, UK). Staph. aureus RN4220 is a restriction-deficient 8325-4 derivative (Kreiswirth et al., 1983). Staph. aureus WCUH29 is an encapsulated pathogenic strain (NCIMB 40771) kindly provided by V. Hryniewicz (Children's University Hospital, Warsaw, Poland). pBluescriptTet is a derivative of pBluescript which does not replicate in Staph. aureus and contains the tetK gene from pT181 (Khan \& Novick, 1983).
Generation of Staph. aureus allelic replacement mutants. A $630 \mathrm{bp}$ upstream and $518 \mathrm{bp}$ downstream region of Staph. aureus bacA were amplified using PCR and sequentially cloned either side of an erythromycin-resistance gene, erm C, from pE194 (Horinouchi \& Weisblum, 1982) in pBluescriptTet in E. coli DH10B. The resulting allelic replacement construct was introduced into Staph. aureus RN4220 by electroporation, and erythromycin- and tetracycline-resistant $\left(\operatorname{Erm}^{\mathrm{R}} \operatorname{Tet}^{\mathrm{R}}\right)$ colonies were picked and confirmed as cointegrants using diagnostic PCR. In the latter, DNA primers designed to hybridize within erm $C$ were paired with primers hybridizing to distal chromosomal sequences to generate DNA products of characteristic size. $\phi 11$ transducing lysates (Novick, 1991) were prepared from cointegrants and used to transduce Staph. aureus RN4220. Erm ${ }^{\mathrm{R}}$ transductants were selected and screened for tetracycline sensitivity $\left(\mathrm{Tet}^{\mathrm{S}}\right)$, and $\mathrm{Erm}^{\mathrm{R}} \mathrm{Tet}^{\mathrm{S}}$ clones were examined by diagnostic PCR and Southern blot analysis to confirm that the expected $898 \mathrm{bp}$ deletion had occurred. The $b a c A$ mutation was $\phi 11$ transduced into the pathogenic Staph. aureus strain WCUH29, and the resulting Erm $^{\mathrm{R}}$ clone was reconfirmed as described above. Sensitivity to osmotic stress was determined by plating Staph. aureus strains on Bacto Staphylococcus medium 110 (Chapman, 1945) and incubating for $12 \mathrm{~h}$ at $37^{\circ} \mathrm{C}$.

Generation of Strep. pneumoniae allelic replacement mutants. A 329 bp upstream and 402 bp downstream region of bacA were PCR-amplified from Strep. pneumoniae 0100993 chromosomal DNA, extracted and purified as previously described (Paton, 1996). The fragments were used to make a construct in which they flanked an erythromycin-resistance gene, ermAM, from pAM $\beta 1$ (Martin et al., 1987), which was used to transform Strep. pneumoniae 0100993 competent cells prepared according to standard protocols. Cells $\left(10^{6}\right)$ were incubated with $1-5 \mu \mathrm{g}$ allelic replacement construct at $30^{\circ} \mathrm{C}$ for $40 \mathrm{~min}$ in $\mathrm{AGCH}$ medium (Lacks, 1966) supplemented with $0.2 \%$ sucrose, $1 \mathrm{mM} \mathrm{CaCl}$ and $1.7 \mu \mathrm{g}$ competence stimulating peptide CSP-1 ml $\mathrm{m}^{-1}$ (Havarstein et al., 1995), then transferred to $37^{\circ} \mathrm{C}$ for $70 \mathrm{~min}$. The transformation mix was incubated for a further $20 \mathrm{~min}$ with $0 \cdot 1 \mathrm{mg}$ erythromycin $\mathrm{ml}^{-1}$; then for $10 \mathrm{~min}$ at $37^{\circ} \mathrm{C}$ with $10 \%$ glycerol; and finally for 10 min on ice. The mix was plated in AGCH medium containing $0 \cdot 3 \%$ sucrose, $0 \cdot 2 \%$ yeast extract, $1 \%$ agar and $1 \mu \mathrm{g}$ erythromycin $\mathrm{ml}^{-1}$, and incubated at $37^{\circ} \mathrm{C}$ for $36 \mathrm{~h}$ in $5 \%$ $\mathrm{CO}_{2} . \mathrm{Erm}^{\mathrm{R}}$ colonies were picked and grown overnight in Todd-Hewitt broth (THB) supplemented with $0.5 \%$ yeast extract. Chromosomal DNA from Strep. pneumoniae 0100993 Erm $^{\mathrm{R}}$ clones was examined using Southern blot analysis and diagnostic PCR to verify that the expected 704 bp chromosomal deletion had occurred.

MIC determination. Antimicrobial agents used in the study were obtained from Sigma. Bacitracin stock solution was made up at $2048 \mu \mathrm{g} \mathrm{ml}^{-1}$ in $5 \%$ DMSO. MICs were determined using the NCCLS recommended procedure for broth microdilution. Strep. pneumoniae strains were tested in cationadjusted Mueller-Hinton broth (MHB) supplemented with $5 \%$ lysed horse blood, while Staph. aureus strains were tested in cation-adjusted MHB. Strep. pneumoniae MICs for bacitracin were also determined in THB with $5 \%$ yeast extract, supplemented where appropriate with $5 \%$ horse serum.

Mouse pyelonephritis (PN) infection using Staph. aureus. Overnight cultures of Staph. aureus WCUH29 or isogenic mutant strains grown at $37^{\circ} \mathrm{C}$ were washed twice in sterile PBS and diluted to an $\mathrm{OD}_{600}$ of $0 \cdot 2$. Note that all optical density measurements on microbial samples were taken with a 
Beckman DU520 spectrophotometer using $1 \mathrm{~cm}$ path length cuvettes.

For each strain used, five female CD-1 mice (18-20 g) were inoculated with $0.2 \mathrm{ml}$ suspension $\left(10^{7}\right.$ bacteria) by tail vein injection. Mice were monitored twice daily for signs of illness and any which appeared moribund were killed prior to the end of the experiment. All animals were killed via $\mathrm{CO}_{2}$ overdose at $5 \mathrm{~d}$ post-inoculation. Both kidneys were removed using aseptic techniques and homogenized in $1 \mathrm{ml}$ PBS. Viable bacteria were enumerated after plating on tryptic soy agar (TSA) plates. The significance of attenuation in the mutant group compared to the wild-type was calculated by $t$-test analysis using a two-sample equal variance (type 2) and a one-tailed distribution.

Mouse respiratory tract infection (RTI) model using Strep. pneumoniae. TSA plates containing $5 \%$ sheep blood were inoculated from frozen stocks of Strep. pneumoniae 0100993 or isogenic mutant strains and grown overnight at $37^{\circ} \mathrm{C}$ in $5 \% \mathrm{CO}_{2}$. Bacteria were recovered from the plates and resuspended in PBS to an $\mathrm{OD}_{600}$ of $0 \cdot 8-1 \cdot 0\left(10^{7}-10^{8}\right.$ bacteria $\left.\mathrm{ml}^{-1}\right)$. For each strain used, five male CBA/J mice (14-16 g) were anaesthetized with $3 \%$ isoflurane, and $50 \mu \mathrm{l}$ of the prepared inoculum was administered by intranasal instillation. The mice were allowed to recover and given food and water ad libitum. Animals were observed three times daily and moribund animals, or those showing signs of cyanosis, hypothermia or staring coat, were killed by $\mathrm{CO}_{2}$ overdose. Surviving animals were killed $48 \mathrm{~h}$ post-infection. The lungs were removed aseptically, homogenized in $1 \mathrm{ml}$ PBS, and enumerated for viable bacteria. The significance of attenuation in the mutant group compared to the wild-type was calculated by $t$-test analysis as described above.

\section{RESULTS}

\section{Identification of bacA homologues in Staph. aureus and Strep. pneumoniae}

A Strep. pneumoniae homologue of the 273 aa E. coli BacA protein (Cain et al., 1993) was identified in translation on contig 81 of Strep. pneumoniae type 4 sequence data obtained from The Institute for Genomic Research (http://www.tigr.org), using BLAST version 2.0.4 software (Altschul et al., 1997). The probable translation start site was chosen by homology and for optimal spacing from the potential ribosome-binding site (Gold et al., 1981). The ORF encodes a putative protein of 281 aa. A potential promoter sequence conforming to the E. coli $\sigma^{70}$ promoter consensus at the -10 and -35 regions was identified 15 bp upstream (Sabelnikov et al., 1995) and the up- and downstream genes, which encode a protein with low homology to invertase proteins and an E. coli $\operatorname{din} X$ homologue, respectively, are both transcribed in the opposite orientation to bacA. A compound BOX element was identified $35 \mathrm{bp}$ downstream of the gene. These repetitive elements are found throughout the Strep. pneumoniae genome, but their function is unknown (Martin et al., 1992).

A Staph. aureus ORF which in translation encodes a 291 aa BacA homologue was identified in library sequence from the pathogenic Staph. aureus strain WCUH29, and the sequence has been submitted to GenBank under accession number AF228662. The gene is preceded by a divergently transcribed $c y d D$ transporter homologue. The downstream ORF encodes a lysine-rich protein of uncertain function, but as it is separated from the bacA gene by $120 \mathrm{bp}$ of intervening DNA it seems unlikely that the two are transcriptionally linked.

Alignment of the Strep. pneumoniae and Staph. aureus BacA-like protein sequences with other BacA homologues demonstrated that the sequences range from 20 to $51 \%$ identical at the protein level. There is particular conservation in two regions, $\mathrm{Ile}^{10}-\mathrm{Leu}^{32}$ and $\mathrm{Ile}^{160}-\mathrm{Ile}^{179}$ (Strep. pneumoniae numbering) as shown in Fig. 1. The Staph. aureus, Strep. pneumoniae and E. coli proteins have very similar Kyte-Doolittle hydrophilicity plots (not shown) including eight potential trans-membrane hydrophobic segments 15-20 aa in length. Composition analysis of the three protein sequences showed that they each contain $50 \%$ hydrophobic amino acids, and that in each case isoleucine and leucine account for $20-25 \%$ of the amino acid residues.

\section{Generation of bacA mutants of Staph. aureus and Strep. pneumoniae}

Constructs for allelic replacement of the bacA homologues of Staph. aureus RN4220 and of the pathogenic strains Staph. aureus WCUH29 and Strep. pneumoniae 0100993 were made by PCR amplification. As described above, the Strep. pneumoniae bacA gene is monocistronic and the Staph. aureus bacA gene does not appear to be transcriptionally linked with its downstream gene, so it is extremely unlikely that gene replacement of either would have a polar effect on expression of neighbouring genes. However, in order to minimize potential polar effects, the PCR primers were chosen so that flanking genes and intergenic regions including potential promoters would remain intact in the deletion mutant. In addition, transcriptional termination signals were removed from the erythromycinresistance gene marker (erm) in each case, and the cassettes were designed to integrate in the same orientation as the target gene in an attempt to ensure transcription of the downstream region.

The Staph. aureus bacA allelic replacement construct was transformed into Staph. aureus RN4220 and $\mathrm{Erm}^{\mathrm{R}}$ $\mathrm{Tet}^{\mathrm{R}}$ cointegrant colonies were obtained. $\phi 11$ transduction was used to resolve the cointegrant and generate $\mathrm{Erm}^{\mathrm{R}}$ bacA allelic replacement mutants of Staph. aureus RN4220 and WCUH29 as described. Similarly, an Erm ${ }^{\mathrm{R}}$ allelic replacement mutant of Strep. pneumoniae 0100993 was generated. The expected chromosomal rearrangements were confirmed using PCR and Southern blot analysis. Serial subcultures of the bacA mutants and their wild-type parent strains were subject to growth curve analysis and microscopy, and exponential-phase cultures were subject to flow cytometric analysis, but no differences in cell size, morphology or growth characteristics at equivalent time points including lag phase and growth rate were detectable (data not shown). It therefore appears that 

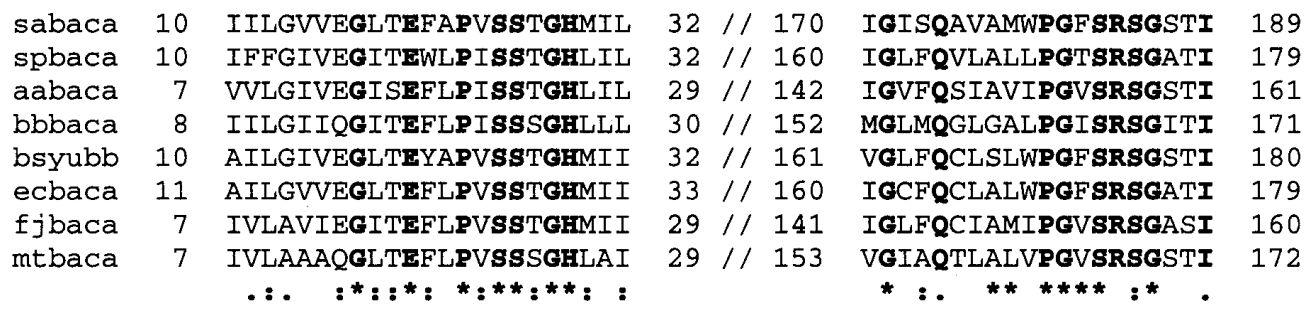

Fig. 1. Two conserved regions in BacA homologues. The Staph. aureus and Strep. pneumoniae BacA homologues (labelled sabaca and spbaca, respectively) were aligned with homologues from Aquifex aeolicus (aabaca; Deckert et al., 1998), Borrelia burgdorferi (bbbaca; Fraser et al., 1997), Bacillus subtilis (bsyubb; Moszer et al., 1995; Kunst et al., 1997), E. coli (ecbaca; Cain et al., 1993), Flavobacterium johnsoniae (fjbaca; M. J. Kempf \& M. J. McBride, GenBank direct submission AAD50462) and Mycobacterium tuberculosis (mtbaca; Cole et al., 1998) using CLUSTALX. Single fully conserved residues are in bold and indicated by an asterisk; residues which are fully conserved within a strongly related group as defined by CLUSTALX are indicated by a double dot; and residues which are fully conserved within a weakly related group are indicated by a single dot.

Table 1. MIC data in $\mu \mathrm{g} \mathrm{ml}^{-1}$ for Strep. pneumoniae and Staph. aureus bacA mutant and parent strains

MICs were determined in MHB with appropriate supplementation as described, except where indicated otherwise. A dash indicates that no MIC was determined.

\begin{tabular}{|c|c|c|c|c|c|c|}
\hline Compound & $\begin{array}{c}\text { Strep. } \\
\text { pneumoniae } \\
0100993\end{array}$ & $\begin{array}{c}\text { Strep. } \\
\text { pneumoniae } \\
0100993 \text { bac } A \\
\text { mutant }\end{array}$ & $\begin{array}{c}\text { Staph. } \\
\text { aureus } \\
\text { WCUH29 }\end{array}$ & $\begin{array}{c}\text { Staph. aureus } \\
\text { WCUH29 bac } A \\
\text { mutant }\end{array}$ & $\begin{array}{l}\text { Staph. } \\
\text { aureus } \\
\text { RN4220 }\end{array}$ & $\begin{array}{c}\text { Staph. aureus } \\
\text { RN4220 bac } A \\
\text { mutant }\end{array}$ \\
\hline Bacitracin & 8 & $0 \cdot 008$ & 32 & 2 & 64 & 4 \\
\hline Bacitracin (THB) & 8 & $0 \cdot 00005$ & - & - & - & - \\
\hline Amoxycillin & $0 \cdot 015$ & $0 \cdot 015$ & 64 & 64 & $0 \cdot 25$ & $0 \cdot 25$ \\
\hline Ceftriaxone & $\leqslant 0 \cdot 015$ & $\leqslant 0 \cdot 015$ & 16 & 16 & 2 & 2 \\
\hline Mupirocin & $0 \cdot 25$ & $0 \cdot 125$ & $0 \cdot 125$ & $0 \cdot 125$ & $0 \cdot 125$ & $0 \cdot 125$ \\
\hline Vancomycin & $0 \cdot 25$ & $0 \cdot 5$ & 1 & $0 \cdot 5$ & $0 \cdot 5$ & 1 \\
\hline Polymyxin B & $>256$ & $>256$ & 64 & 64 & 64 & 64 \\
\hline Cefuroxime & $0 \cdot 015$ & $0 \cdot 015$ & 8 & 8 & 0.5 & $0 \cdot 5$ \\
\hline Tetracycline & $0 \cdot 5$ & $0 \cdot 5$ & $0 \cdot 5$ & $0 \cdot 5$ & $0 \cdot 5$ & $0 \cdot 5$ \\
\hline Chloramphenicol & 4 & 8 & $>8$ & $>8$ & 8 & 8 \\
\hline Gentamicin & 8 & 8 & $0 \cdot 5$ & $0 \cdot 5$ & $0 \cdot 5$ & $0 \cdot 25$ \\
\hline Kanamycin & 64 & 32 & 16 & 16 & 2 & 4 \\
\hline Spectinomycin & $>8$ & $>8$ & $>8$ & $>8$ & $>8$ & $>8$ \\
\hline Ciprofloxacin & 2 & 2 & $0 \cdot 5$ & $0 \cdot 25$ & 0.5 & $0 \cdot 25$ \\
\hline
\end{tabular}

the $b a c A$ gene is not required for the viability in vitro of either Staph. aureus or Strep. pneumoniae. The Staph. aureus WCUH29 and RN4220 bacA mutants and their parent strains, which are salt-tolerant (Vijaranakul et al., 1997), were also plated on high osmotic strength medium containing $7 \cdot 5 \% \mathrm{NaCl}$ but showed no differences in growth.

\section{Bacitracin susceptibility of mutants}

The MICs of the Staph. aureus WCUH29 and RN4220 bacA mutants, the Strep. pneumoniae 0100993 bacA mutant and their parent strains for a panel of antibiotics including bacitracin were determined (Table 1). Both
Staph. aureus bacA mutants showed a 16 -fold increase in susceptibility to bacitracin relative to their parent strains. In the case of the Strep. pneumoniae 0100993 bacA mutant (but not the wild-type strain), it was noted that MICs were significantly lower than wild-type but varied over 5-6 doubling dilutions, depending on the type of media and the solvent used for bacitracin. The mutant gave an MIC for bacitracin of $0.008 \mu \mathrm{g} \mathrm{ml}^{-1}$ in $\mathrm{MHB}$, representing a 1000-fold increase in susceptibility compared to the parent strain; whereas in THB, the mutant reproducibly gave an MIC of $0.00005 \mu \mathrm{g} \mathrm{ml}-1$ both with and without $5 \%$ horse serum, representing a 160000 -fold increase in susceptibility. No change in susceptibility was observed for other test compounds. 

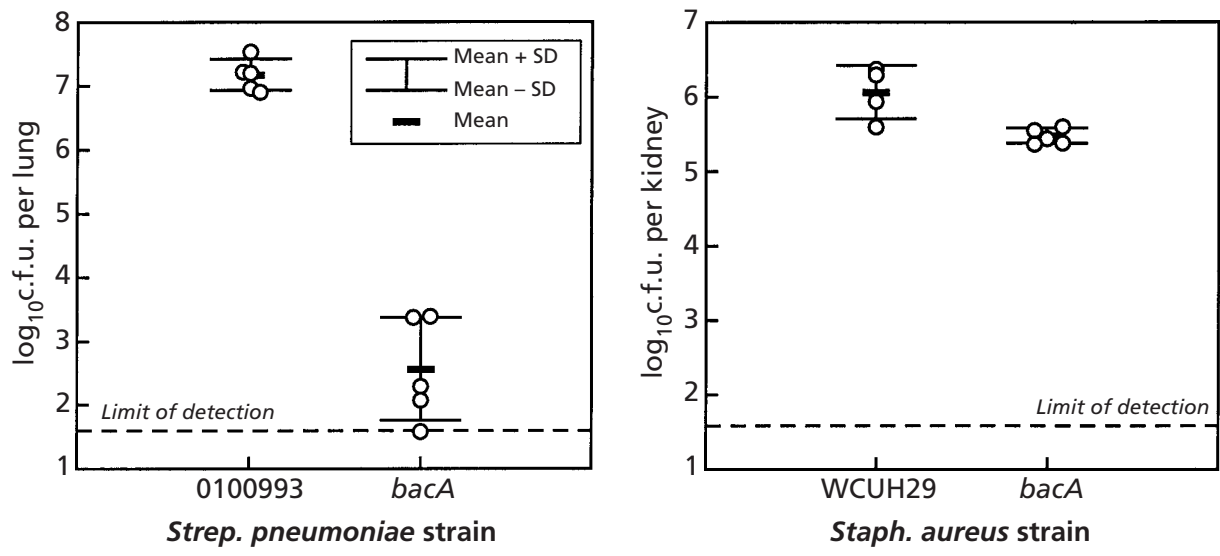

Fig. 2. In vivo analysis of bacA mutant strains. Infection models are mouse RTI for Strep. pneumoniae, and mouse haematogenous PN for Staph. aureus. For each model, the wild-type strain is designated by strain name and the mutant strain by bacA. Each mutant was tested in a five-animal group in comparison with a wild-type control group (one animal in the Staph. aureus WCUH29 control group died at $48 \mathrm{~h}$ ).

\section{Characterization of mutants in a mouse model}

The Strep. pneumoniae 0100993 and Staph. aureus WCUH29 bacA mutants were tested in standard murine infection models (Fig. 2). Bacterial load in harvested tissue samples was enumerated as bacterial numbers in c.f.u. to directly reflect the capacity of the bacteria to grow and survive within the host, as this provides the most accurate assessment of attenuation. The Strep. pneumoniae bacA mutant was used to infect groups of mice intranasally using a standard murine RTI model, and the lungs were harvested $48 \mathrm{~h}$ post-infection. The bac $A$ mutant group gave a mean bacterial count of $2 \cdot 6$ $\log _{10}$ c.f.u. per lung, representing a $4.6 \log _{10}$ attenuation in comparison with wild-type Strep. pneumoniae 0100993, which gave a mean count of $7 \cdot 2 \log _{10}$ c.f.u. per lung. In a Staph. aureus mouse haematogenous PN infection model, the Staph. aureus bacA mutant showed a $0.6 \log$ attenuation $5 \mathrm{~d}$ post-infection, giving a mean bacterial count of $5 \cdot 5 \log _{10}$ c.f.u. per kidney as compared to $6 \cdot 1 \log _{10}$ c.f.u. per kidney with the wild-type Staph. aureus WCUH29 infection control. $t$-test analysis showed that both mutants were significantly attenuated $(P \leqslant 0 \cdot 01)$. Comparison of these data with the behaviour in these models of Strep. pneumoniae and Staph. aureus strains mutated in a variety of different genes affecting cell metabolism or virulence (data not shown) indicated that the Strep. pneumoniae bacA mutant is approaching the maximum attenuation of 6 logs which has been detected in the Strep. pneumoniae RTI model; while the Staph. aureus bacA mutant is only slightly impaired in comparison to the maximum attenuation we have detected in the Staph. aureus PN model, which is 2.5 logs.

\section{DISCUSSION}

Homologues of the probable E. coli undecaprenol kinase enzyme BacA are widespread among eubacteria. The Strep. pneumoniae and Staph. aureus bacA gene products described here are, respectively, $29 \%$ and $43 \%$ identical to the E. coli bacA gene product, and the unusually hydrophobic properties of these proteins are consistent with their proposed role as membrane-bound undecaprenol kinase enzymes. Although the size of purified Staph. aureus undecaprenol kinase enzyme was previously estimated by SDS-PAGE to be $17000 \mathrm{Da}$ (Sandermann \& Strominger, 1971, 1972) while the Staph. aureus bacA gene encodes a product of $32000 \mathrm{Da}$, both proteins are likely to behave anomalously during chromatographic purification and SDS-PAGE analysis due to their high hydrophobicity, and it is therefore entirely possible that they are one and the same. This is supported by protein composition analysis, as amino acid frequencies in the Staph. aureus undecaprenol kinase enzyme determined by physical methods (Sandermann \& Strominger, 1971) are strikingly similar to those found in the bacA gene product. For example, the frequency of non-polar amino acids $(\mathrm{P}, \mathrm{A}, \mathrm{V}, \mathrm{I}, \mathrm{M}, \mathrm{L}$ and $\mathrm{F}$ ) estimated for the isolated enzyme following acid hydrolysis was $57.8 \%$, while the BacA protein described here contains $54.7 \%$ non-polar residues.

Further evidence that the bacA gene product is involved in $\mathrm{C}_{55}$ lipid recycling is provided by the observation that the Strep. pneumoniae bacA mutant is hypersensitive to bacitracin, while its susceptibility to other cell-wall- and cell-membrane-targeting antibiotics, including amoxycillin, polymyxin B and vancomycin, remains unchanged. However, the MIC of the Strep. pneumoniae bacA mutant for bacitracin was found to be highly dependent on media and conditions. It has been reported that addition of $5 \%$ sheep blood to $\mathrm{MHB}$ increases enterococcal MICs for bacitracin (Butaye et al., 1998), and this is consistent with our observation that the MIC of the mutant for bacitracin is higher in blood-containing media, although it is unaffected by serum concentration. As the higher MIC of wild-type Strep. pneumoniae did not vary, it appears that at lower bacitracin concentrations some medium component is 
binding to and sequestering the antibiotic. It is, however, clear that the bacA mutation considerably increases Strep. pneumoniae susceptibility to bacitracin, suggesting that it directly and specifically affects the role of UPP in this organism. We hypothesize that in the bacA mutant, UP is produced solely by dephosphorylation of UPP. Hence, when this intermediate is sequestered by bacitracin, UP supplies are rapidly recycled out of circulation and cell wall biosynthesis ceases altogether.

The bacA mutants and their parent strains showed no detectable differences in morphology, growth parameters or (in the case of Staph. aureus) sensitivity to osmotic stress which might indicate a deficiency in cell wall synthesis in the absence of bacitracin. However, the Strep. pneumoniae bacA mutant was severely attenuated in a mouse RTI infection model. This suggests that, although the bacA mutant cells were healthy in vitro, the absence of undecaprenol kinase causes metabolic changes sufficient to compromise infectivity. The Staph. aureus WCUH29 bacA mutant also showed reduced infectivity in a murine infection model and increased susceptibility to bacitracin, but the effects of the mutation were surprisingly slight in comparison to Strep. pneumoniae. Although we have shown that the undecaprenol kinase protein described by Sandermann \& Strominger (1971) is very likely to be the bacA gene product, the possibility that Staph. aureus contains a second, uncharacterized, undecaprenol kinase activity cannot be ruled out. Previous studies have shown that in some organisms the size of the undecaprenol pool varies according to growth phase (Thorne, 1973), so it is also possible that the size of the pool and the importance of undecaprenol as an alternative source of UP also vary between organisms. Alternatively, environmental stresses specific to the Strep. pneumoniae infection model may exacerbate the deficiencies of the Strep. pneumoniae bacA mutant in establishing and/or maintaining infection.

Novel agents targeting Strep. pneumoniae are of particular interest, as this organism is the most common cause of community-acquired pneumonia requiring hospitalization, with high morbidity and mortality rates (Marrie, 1999). It also causes meningitis, acute otitis media and acute exacerbations of chronic bronchitis, and increasing rates of resistance to common antibiotics including penicillins and macrolides are reported. Our data suggest that an inhibitor of BacA would not only reduce Strep. pneumoniae virulence in its own right, but would also have a synergistic effect on bacitracin activity which is potentially sufficient to reduce the effective bacitracin dose to below toxic levels. If so, such an antibiotic combination could theoretically be used without toxic effect in systemic applications for which bacitracin monotherapy is unsafe.

Finally, in this work we have followed nomenclature used by Cain et al. (1993). However, we note that the gene name bacA is not unique, as it is also used for bacitracin synthetase 1 of Bacillus licheniformis, and for a transport protein involved in bacteroid synthesis in Rhizobium spp. We therefore propose that consideration is given to an alternative designation (for example $b s d A$, for bacitracin susceptibility determinant) for this gene.

\section{ACKNOWLEDGEMENTS}

Preliminary Strep. pneumoniae sequence data were obtained from The Institute for Genomic Research through the website at http://www.tigr.org. Sequencing of Strep. pneumoniae type 4 was accomplished with support from TIGR/NIAID/ MGRI. We are grateful to Leroy Voelker and Ken Coleman for helpful discussions, and Wendy Crowell for graphics assistance.

\section{REFERENCES}

Altschul, S. F., Madden, T. L., Schaffer, A. A., Zhang, J., Zhang, Z., Miller, W. \& Lipman, D. J. (1997). Gapped BLAST and PSI-BLAST : a new generation of protein database search programs. Nucleic Acids Res 25, 3389-3402.

Anderson, R. G., Hussey, H. \& Baddiley, J. (1972). The mechanism of wall synthesis in bacteria. The organization of enzymes and isoprenoid phosphates in the membrane. Biochem J 127, 11-25.

Apfel, C. M., Takacs, B., Fountoulakis, M., Stieger, M. \& Keck, W. (1999). Use of genomics to identify bacterial undecaprenyl pyrophosphate synthetase: cloning, expression, and characterization of the essential uppS gene. J Bacteriol 181, 483-492.

Baddiley, J. (1973). Lipid intermediates in the biosynthesis of bacterial cell-wall components. Biochem Soc Trans 1, 1026-1028.

Butaye, P., Devriese, L. A. \& Haesebrouck, F. (1998). Effects of different test conditions on MICs of food animal growthpromoting antibacterial agents for enterococci. J Clin Microbiol 36, 1907-1911.

Cain, B. D., Norton, P. J., Eubanks, W., Nick, H. S. \& Allen, C. M. (1993). Amplification of the bacA gene confers bacitracin resistance to Escherichia coli. J Bacteriol 175, 3784-3789.

Chapman, G. H. (1945). The significance of sodium chloride in studies of staphylococci. J Bacteriol 50, 201-203.

Cole, S. T., Brosch, R., Parkhill, J. \& 39 other authors (1998). Deciphering the biology of Mycobacterium tuberculosis from the complete genome sequence. Nature 393, 537-544.

Cornelissen, F. \& Van den Bossche, H. (1983). Synergism of the antimicrobial agents miconazole, bacitracin and polymyxin $\mathrm{B}$. Chemotherapy 29, 419-427.

Deckert, G., Warren, P. V., Gaasterland, T. \& 12 other authors (1998). The complete genome of the hyperthermophilic bacterium Aquifex aeolicus. Nature 392, 353-358.

Drablos, F., Nicholson, D. G. \& Ronning, M. (1999). EXAFS study of zinc coordination in bacitracin A. Biochim Biophys Acta 1431, 433-442.

Fraser, C. M., Casjens, S., Huang, W. M. \& 35 other authors (1997). Genomic sequence of a Lyme disease spirochete, Borrelia burgdorferi. Nature 390, 580-586.

Gold, L., Pribnow, D., Schneider, T., Shinedling, S., Singer, S. B. \& Stormo, G. (1981). Translation initiation in prokaryotes. Annu Rev Microbiol 25, 365-403.

Goldman, R. \& Strominger, J. L. (1972). Purification and properties of $\mathrm{C}_{55}$-isoprenol pyrophosphate phosphatase from Micrococcus lysodeikticus. J Biol Chem 247, 5116-5122. 
Havarstein, L. S., Coomaraswamy, G. \& Morrison, D. A. (1995). An unmodified heptadecapeptide pheromone induces competence for genetic transformation in Streptococcus pneumoniae. Proc Natl Acad Sci USA 92, 11140-11144.

Higashi, Y., Siewert, G. \& Strominger, J. L. (1970a). Biosynthesis of the peptidoglycan of bacterial cell walls. J Biol Chem 245, 3683-3690.

Higashi, Y., Strominger, J. L. \& Sweeley, C. C. (1970b). Biosynthesis of the peptidoglycan of bacterial cell walls. XXI. Isolation of free $\mathrm{C}_{55}$-isoprenoid alcohol and of lipid intermediates in peptidoglycan synthesis from Staphylococcus aureus. J Biol Chem 245, 3697-3702.

Horinouchi, S. \& Weisblum, B. (1982). Nucleotide sequence and functional map of pE194, a plasmid that specifies inducible resistance to macrolide, lincosamide, and streptogramin type B antibiotics. J Bacteriol 150, 804-814.

Kanof, N. B. (1970). Bacitracin and tyrothricin. Med Clin N Am 54, 1291-1293.

Khan, S. \& Novick, R. P. (1983). Complete nucleotide sequence of pT181, a tetracycline-resistance plasmid from Staphylococcus aureus. Plasmid 10, 251-259.

Kreiswirth, B. N., Lofdahl, S., Belley, M. J., O'Reilly, M., Shlievert, P. M., Bergdoll, M. S. \& Novick, R. P. (1983). The toxic shock syndrome exotoxin structural gene is not detectably transmitted by a prophage. Nature $\mathbf{3 0 5}, \mathbf{7 0 9 - 7 1 2 . ~}$

Kunst, F., Ogasawara, N., Moszer, I. \& 148 other authors (1997). The complete genome sequence of the Gram-positive bacterium Bacillus subtilis. Nature 390, 249-256.

Lacks, S. (1966). Integration efficiency and genetic recombination in pneumococcal transformation. Genetics 53, 207-235.

Marrie, T. J. (1999). Pneumococcal pneumonia: epidemiology and clinical features. Semin Respir Infect 14, 227-236.

Martin, B., Alloing, G., Mejean, V. \& Claverys, J. P. (1987). Constitutive expression of erythromycin resistance mediated by the ermAM determinant of plasmid pAM $\beta 1$ results from deletion of $5^{\prime}$ leader peptide sequences. Plasmid 18, 250-253.

Martin, B., Humbert, O., Camara, M. \& 10 other authors (1992). A highly conserved repeated DNA element located in the chromosome of Streptococcus pneumoniae. Nucleic Acids Res 20, 3479-3483.

Moszer, I., Glaser, P. \& Danchin, A. (1995). Subtilist: a relational database for the Bacillus subtilis genome. Microbiology 141, 261-268.

Navarre, W. W. \& Schneewind, O. (1999). Surface proteins of Gram-positive bacteria and mechanisms of their targeting to the cell wall envelope. Microbiol Mol Biol Rev 63, 174-229.
Novick, R. P. (1991). Genetic systems in Staphylococci. Methods Enzymol 204, 587-637.

Paton, J. C. (1996). The contribution of pneumolysin to the pathogenicity of Streptococcus pneumoniae. Trends Microbiol 4, 103-106.

Reusch, V. M., Jr (1984). Lipopolymers, isoprenoids, and the assembly of the gram-positive cell wall. Crit Rev Microbiol 11, 129-155.

Reusch, V. M., Jr \& Panos, A. (1976). Defective synthesis of lipid intermediates for peptidoglycan formation in a stabilized L-form of Streptococcus pyogenes. J Bacteriol 126, 300-311.

Sabelnikov, A. G., Greenberg, B. \& Lacks, S. A. (1995). An extended -10 promoter alone directs transcription of the $D p n I I$ operon of Streptococcus pneumoniae. J Mol Biol 250, 144-155.

Sandermann, H., Jr \& Strominger, J. L. (1971). $\mathrm{C}_{55}$-isoprenoid alcohol phosphokinase: an extremely hydrophobic protein from the bacterial membrane. Proc Natl Acad Sci USA 68, 2441-2443.

Sandermann, H., Jr \& Strominger, J. L. (1972). Purification and properties of $\mathrm{C}_{55}$-isoprenoid alcohol phosphokinase from Staphylococcus aureus. J Biol Chem 247, 5123-5131.

Shimizu, N., Koyama, T. \& Ogura, K. (1998). Molecular cloning, expression, and purification of undecaprenyl diphosphate synthase: no sequence similarity between $\mathrm{E}$ - and Z-prenyl diphosphate synthases. J Biol Chem 273, 19476-19481.

Stone, K. J. \& Strominger, J. L. (1971). Mechanism of action of bacitracin: complexation with metal ion and $\mathrm{C}_{55}$-isoprenyl pyrophosphate. Proc Natl Acad Sci USA 68, 3223-3227.

Stone, K. J. \& Strominger, J. L. (1972). Inhibition of sterol biosynthesis by bacitracin. Proc Natl Acad Sci USA 69, 1287-1289.

Storm, D. R. \& Strominger, J. L. (1973). Complex formation between bacitracin peptides and isoprenyl pyrophosphates. J Biol Chem 248, 3940-3945.

Thorne, K. J. I. (1973). Identification of prenol intermediates of wall biosynthesis in growing cells of Lactobacillus plantarum. J Bacteriol 116, 235-244.

Toscano, W. A. \& Storm, D. R. (1982). Bacitracin. Pharmacol Ther 16, 199-210.

Umbreit, J. N., Stone, K. J. \& Strominger, J. L. (1972). Isolation of polyisoprenyl alcohols from Streptococcus faecalis. J Bacteriol 112, 1302-1305.

Vijaranakul, U., Nadakavukaren, M. J., Bayles, D. O., Wilkinson, B. J. \& Jayaswal, R. K. (1997). Characterization of an $\mathrm{NaCl}-$ sensitive Staphylococcus aureus mutant and rescue of the $\mathrm{NaCl}$ sensitive phenotype by glycine betaine but not by other compatible solutes. Appl Environ Microbiol 63, 1889-1897.

Received 14 February 2000; revised 3 April 2000; accepted 25 April 2000. 